\title{
Autoridade e Disciplina em Tempos de Autoritarismo: lições de Paulo Freire
}

\author{
Authority and Discipline in Times of Authoritarianism: lessons by \\ Paulo Freire
}

\section{Autoridad y Disciplina en Tiempos de Autoritarismo: lecciones de} Paulo Freire

\author{
Vanessa Campos Mariano Ruckstadter \\ http://orcid.org/0000-000 I-6072-3700 \\ Flávio Massami Martins Ruckstadter² \\ https://orcid.org/0000-0002-0430-0866 \\ Gabriely Cristine de Souza ${ }^{3}$ \\ https://orcid.org/0000-0002-3754-6897
}

Resumo: Este texto tem como objetivo analisar as contribuições do pensamento de Paulo Freire (1921 - 1997) no debate acerca da autoridade e disciplina no contexto escolar. Essa questão tem sido retomada com ênfase nos últimos anos no país e tem se concretizado no âmbito das políticas públicas em torno da militarização de escolas públicas. Assim, este artigo propõe pensarmos: a única saída para uma reorganização escolar em torno da disciplina e qualidade da educação seria a militarização? A hipótese é a de que o pensamento freiriano pode ajudar a construir uma contraofensiva a partir da autoridade e da disciplina, mas sem deixar de lado algo fundamental em uma democracia: a liberdade. O itinerário será o de apresentar vida e obra do autor para, na sequência, analisar os conceitos freirianos de autoridade, disciplina, liberdade e autonomia. Uma das lições

I Doutora em Educação. Professora Adjunta do Centro de Ciências Humanas e da Educação. Professora do Programa de Pós-Graduação em Educação e Colegiado de Pedagogia. Universidade Estadual do Norte do Paraná, campus Jacarezinho. E-mail: vanessaruckstadter@uenp.edu.br.

2 Doutor em Educação. Professor Adjunto do Centro de Ciências Humanas e da Educação. Professor do Programa de Pós-Graduação em Educação e Colegiado de História. Universidade Estadual do Norte do Paraná, campus Jacarezinho. E-mail: flavioruckstadter@uenp.edu.br.

3 Aluna do Curso de História. Bolsista de Iniciação Científica da Fundação Araucária. Universidade Estadual do Norte do Paraná, campus Jacarezinho. E-mail: gabysouza090198@gmail.com.

Olhar de professor, Ponta Grossa, v. 24, p. I-2I, e-16762.040, 202 I.

Disponível em <https://revistas2.uepg.br/index.php/olhardeprofessor> 
freirianas é a de que a autoridade deve estar a serviço da liberdade e, de forma dialógica, será possível fortalecer e defender uma escola pública plural, democrática, com qualidade e como direito inalienável para todos e todas. Palavras-chave: Educação. Paulo Freire. Disciplina.

\begin{abstract}
This text aims to analyze the contributions of Paulo Freire' thought (1921-1997) to the debate about authority and discipline in the school context. This question has been readdressed with emphasis over the last few years in the country and has become materialized in the scope of the public policies regarding the militarization of public schools. In this sense, this article proposes a reflection upon: would the militarization of the public schools be the only way to achieve the reorganization of schools around discipline and quality of education? The hypothesis is that Freire's thought can help to build a counter offensive from a proposal that aims at authority and discipline, but without leaving aside something fundamental in democracy, namely freedom. This text's itinerary is to present Paulo Freire's life and work and, in the sequence, to analyze Freire's concepts of authority, discipline, freedom and autonomy. One of Freire's lessons is that authority should be at service of freedom, thus with a dialogical approach, it will be possible to strengthen and defend a public school that is plural, democratic and high quality, and as an inalienable right guaranteed to everyone.
\end{abstract}

Key words: Education. Paulo Freire. Discipline.

Resumen: Este texto tiene como objetivo analizar las contribuciones del pensamiento de Paulo Freire (I92I1997) en los debates acerca de la autoridad y disciplina en el contexto escolar. Esa cuestión ha sido retomada con énfasis en los últimos años en el país y se ha concentrado en el ámbito de las políticas públicas alrededor de la militarización de las escuelas públicas. En este sentido, este artículo propone pensar: ¿La única salida para una reorganización escolar en torno de la disciplina y cualidad de la educación sería la militarización de las escuelas públicas? La hipótesis es la que el pensamiento freiriano puede ayudar a construir una contra ofensiva a partir de una propuesta que logre autoridad y disciplina, pero sin dejar de lado algo fundamental en una democracia: la libertad. El itinerario de este texto es presentar la vida y obra de Paulo Freire para, en la secuencia, analizar los conceptos freirianos de autoridad, disciplina, libertad y autonomía. Una de las lecciones freirianas es que la autoridad debe estar al servicio de la libertad, y que, de forma dialógica, sea posible fortalecer y defender una escuela pública plural, democrática, con cualidad y como derecho inalienable para todos y todas.

Palabras clave: Educación. Paulo Freire. Disciplina.

\title{
Introdução ${ }^{4}$
}

Em uma rápida busca nas notícias veiculadas pela imprensa sobre violência no contexto escolar encontramos um número significativo de reportagens acerca da defesa da militarização das escolas públicas e de projetos de alguns estados da federação. Em 05 de setembro de 2019 o atual presidente da República assinou um decreto que regulamentou a adesão dos Estados ao Programa Nacional das Escolas Cívico-Militares. Essa adesão, que por hora é voluntária, pode se tornar modelo, segundo o discurso do atual governo. Em mapa divulgado na mesma reportagem, os 3 estados com maior número desse tipo de escola eram Goiás, com 59, seguido por Minas Gerais, com 30 escolas, e Roraima com 19, todas elas estaduais (VARGAS, 2019). No Estado do Paraná, o atual governador do Estado, Ratinho Junior, anunciou a adesão ao Programa em 26 de outubro de 2020 (BEM PARANÁ, 2020).

No site do Ministério da Educação há uma página dedicada ao Programa Nacional das Escolas Cívico-Militares. Trata-se de uma iniciativa em conjunto com o Ministério da Defesa e que apresenta

\footnotetext{
${ }^{4}$ Resultado de uma Pesquisa de Iniciação Científica financiada pela Fundação Araucária/PR entre os anos de 2019 e 2020.
}

Olhar de professor, Ponta Grossa, v. 24, p. I-2I, e-16762.040, 202 I.

Disponível em <https://revistas2.uepg.br/index.php/olhardeprofessor> 
Vanessa Campos Mariano Ruckstadter, Flávio Massami Martins Ruckstadter e Gabriely Cristine de Souza como meta implantar 216 escolas desse tipo no país até o ano de 2023. A proposta é de que os militares da reserva atuem no apoio à gestão escolar e pedagógica. A implantação do projeto-piloto por adesão dos estados da federação e municípios aconteceu a partir do ano de 2020. Algumas premissas deste tipo de escola segundo peça publicitária audiovisual do MEC são: "Respeito ao Professor, a disciplina nas salas de aula e maior apoio aos alunos” (MEC, 2020).

Diante do crescimento recente da adesão pelos estados e municípios a esse tipo de escola, bem como da existência de um Programa Nacional e da meta de que ele se torne modelo para todo o país, pode-se questionar: a militarização das escolas se apresenta como única possibilidade para enfrentar a indisciplina e a violência nas escolas? Ou ainda, para seguir a lógica freiriana em A Pedagogia da Autonomia (1996): ensinar exige disciplina e autoridade? Nesse sentido, este texto apresenta uma possibilidade contra-hegemônica para o debate a partir do pensamento do Patrono da Educação Brasileira, Paulo Freire (1921-1997).

A obra de Paulo Freire é vasta e densa e por esta razão, este texto propõe a análise dos conceitos elencados a partir do livro A Pedagogia da Autonomia (1996). Justifica-se a escolha a partir das palavras prefaciadas na própria obra pela professora Édina Castro de Oliveira:

Num momento de aviamento e de desvalorização do trabalho do professor em todos
os níveis, a pedagogia da autonomia nos apresenta elementos constitutivos da
compreensão da prática docente enquanto dimensão social da formação humana.
Para além da redução ao aspecto estritamente pedagógico e marcado pela natureza
política de seu pensamento, Freire, adverte-nos para a necessidade de assumirmos
uma postura vigilante contra todas as práticas de desumanização. Para tal o saber-
fazer da auto reflexão crítica e o saber-ser da sabedoria exercitados
permanentemente, podem nos ajudar a fazer a necessária leitura crítica das
verdadeiras causas da degradação humana e da razão de ser do discurso fatalista da
globalização (FREIRE, 1996, p. 7).

Antes, contudo, da análise dos conceitos propriamente ditos, é necessário destacar que Paulo Freire dedicou sua vida à educação e elaborou um método de alfabetização para jovens e adultos conhecido e reconhecido em todo mundo. Mas seu pensamento vai além de um método de ensino. Esse método está embasado em uma concepção de educação e de mundo.

A partir de uma investigação bibliográfica e documental, propomo-nos a responder às questões levantadas. Bibliográfica, pois dialoga com estudiosos do pensamento freiriano, tais como Brandão (2014), Scocuglia (2019) e Beisegel (2010). Documental, uma vez que parte do texto do próprio Paulo Freire (1996), a fim de analisar os conceitos por ele apresentados em sua obra Pedagogia da Autonomia. Além disso, insere autor e obra em seu contexto histórico para discutir como as ideias apresentadas por ele se situam em relações políticas, econômicas, sociais e culturais específicas. Isso significa afirmar que todo documento é portador de um discurso ideológico, e, portanto, não é neutro ou porta uma verdade. Partimos do pressuposto de que o pensamento educacional de um autor guarda profundas 
relações com suas experiências de vida. Nesse sentido, este artigo inicia com uma aproximação da vida e obra de Paulo Freire que nos possibilita a contextualização seu pensamento educacional, especificamente sobre a questão da autoridade e da disciplina, na segunda parte deste texto.

\section{A vida e a obra de um educador}

O professor Paulo Freire nasceu Paulo Reglus Neves Freire, na cidade de Recife, no dia 19 de setembro de 1921. O educador acreditava que, antes de ir para a escola, a criança já aprendia com o mundo em que vive. Ele mesmo aprendeu a ler e a escrever riscando palavras no chão de sua casa em Recife, assim, "elas aprendem convivendo com os outros: com as plantas, com os bichos e com as pessoas, com tudo e com todos com quem a gente reparte momentos alegres e momentos tristes da nossa vida" (BRANDÃO, 2014, p. 19).

Carlos Rodrigues Brandão (20l4), que foi amigo de Paulo Freire, expõe que ele refletia muito sobre a questão da diferença entre "falar para alguém" e "falar com alguém". Em maio de 1960, ○ educador participou do Movimento de Cultura Popular (MCP) de Recife, assumindo a direção da Divisão de Pesquisas. Ademais, em fevereiro de 1962, Freire assumiu a direção do Serviço de Extensão Cultural (SEC) da Universidade do Recife (RUCKSTADTER; SOUZA, 2020).

Sobre as ideias do MCP, Brandão ressalta que:

O MCP era uma grande "escola aberta de cultura". O sonho das pessoas do MCP era trazer às crianças e aos adultos dos bairros pobres do Recife, das favelas, das beiras dos rios, tudo o que pudesse ser visto e ouvido de bom e de bonito. [...] Não era só levar para a gente dos bairros pobres aquilo que se podia assistir nos dos ricos. $O$ pessoal do MCP sabia que todas as pessoas, todas as famílias, todas as comunidades tinham a sua própria cultura. [...] E, sendo essa gente as mulheres e os homens das classes trabalhadoras do Brasil, os professores e os artistas do MCP começaram a dar a tudo que as pessoas simples do campo e da cidade sentiam, pensavam, viviam, faziam e criavam o nome de "cultura popular" [...] De um lado, o MCP queria "levar a cultura ao povo". Mas, de outro, queria "aprender com o povo a sua cultura (BRANDÃO, 20I4, p. 36-37).

Paulo Freire começou a trabalhar com a "alfabetização de adultos" no próprio MCP. No Brasil, em 1963, Paulo Freire teve seu método de alfabetização de adultos divulgado em ampla campanha publicitária promovida pela Secretaria de Educação do Estado do Rio Grande do Norte, onde, no interior, em Angicos, teve início sua primeira experiência (BEISIEGEL, 20I0). A obra Educação como prática da liberdade, de 1967, traz, assim como Pedagogia do Oprimido, publicada em 1968, suas preocupações e as propostas metodológicas para a alfabetização de adultos, na tentativa de formular as primeiras matrizes de uma "pedagogia da resistência" contra os processos de opressão desenvolvidos nos anos 1960 por toda a América Latina (SCOCUGLIA, 2019).

Olhar de professor, Ponta Grossa, v. 24, p. I-2I, e-16762.040, 202 I.

Disponível em <https://revistas2.uepg.br/index.php/olhardeprofessor> 
Com o bom resultado e a repercussão de sua experiência de alfabetização, o educador pernambucano foi designado para presidir a Comissão Nacional de Cultura Popular instituída por portaria do ministro Paulo de Tarso, em 8 de julho de 1963, sendo também chamado a assumir a coordenação nacional do Plano Nacional de Alfabetização, criado na passagem de 1963 para 1964. Dessa forma, como esclarece Brandão (20l4), Freire e sua equipe eram professores preocupados com tudo o que viam à sua volta, e havia tanta pobreza, tanta desigualdade por toda a parte.

Esses educadores brasileiros, mesmo com a consciência de que a educação não muda o mundo, entendiam que a educação ajuda a mudar as pessoas, ensinando-as a saber ler melhor, ter mais consciência do que está acontecendo, pensar melhor e agir melhor juntas e as pessoas podem, sim, mudar o mundo. Sendo assim, nos anos 1960, essas ideias cresceram e se espalharam pelo país de modo que, em muitos lugares, havia gente participando de algum "movimento de cultura popular" (RUCKSTADTER; SOUZA, 2020).

As ideias da Educação Popular foram desenvolvidas nesse período e, dentro delas, a alfabetização de mulheres e de homens, jovens, adultos e idosos, com o Método Paulo Freire. O governo federal, em Brasília, resolveu começar uma "campanha de alfabetização" em todo o país. Seria um trabalho nas escolas, usando o método de ensino de ler e escrever do professor Paulo Freire. Seria uma campanha enorme, do Rio Grande do Sul ao Amapá. Seria, mas essa iniciativa foi interrompida, juntamente com toda mobilização que estava sendo realizada em torno da Educação Popular, pelo golpe militar de 31 de março de 1964 (RUCKSTADTER; SOUZA, 2020).

Nesse contexto, em que muita gente foi presa Brasil afora, o educador Paulo Freire foi preso e depois foi exilado. Freire passou mais de 15 anos no exílio, viajando para outros países sem poder retornar. Depois de viver, primeiramente, algum tempo na Bolívia, o professor Paulo foi para o Chile. No Chile concluiu, em 1965, a redação do livro Educação como prática da liberdade, cuja $I^{\circ}$ edição brasileira foi publicada em 1967. Neste livro, Freire expõe a situação da sociedade brasileira, transitando de uma condição para outra, da passagem da consciência mágica, que é própria da sociedade fechada, predominante nos meios rurais, para a consciência transitivo-ingênua. Essa passagem dá-se automaticamente com a mudança provocada pelo processo de industrialização e urbanização, que introduz rachaduras na sociedade fechada, provocando a emersão do povo na vida política (RUCKSTADTER; SOUZA, 2020). Por sua vez, a passagem da consciência transitivo-ingênua para a transitivo-crítica não se dá automaticamente, mas depende de um trabalho educativo voltado intencionalmente para esse objetivo (SAVIANI, 20I3).

A sociedade brasileira dos anos de 1960 estava, segundo a concepção de Freire, transitando de uma sociedade fechada para uma sociedade aberta. Nessa situação, a educação estaria a serviço da domesticação e da alienação ou estaria a serviço da conscientização e da liberdade. Desse modo, seu

Olhar de professor, Ponta Grossa, v. 24, p. I-2I, e-16762.040, 202 I.

Disponível em <https://revistas2.uepg.br/index.php/olhardeprofessor> 
método foi criado seguindo a ideia da educação a serviço da conscientização, que seria um recurso para a passagem da consciência transitivo-ingênua para a transitivo-crítica (RUCKSTADTER; SOUZA, 2020).

É em vista desse objetivo que foi criado um método de alfabetização ativo, dialogal, crítico e "criticizador". Esse método, no entanto, é apenas um aspecto de uma proposta pedagógica mais ampla enraizada na tradição mais autêntica do existencialismo cristão, em diálogo com algumas contribuições do marxismo (SAVIANI, 20I3, p. 335).

Afonso Celso Scocuglia explica, em seu livro, A história das ideias de Paulo Freire e a atual crise de paradigmas (2019), que é válido compreender o contexto em que Freire estava inserido. Então, é esclarecedor apontar que o professor iniciou a produção de suas obras com o horizonte da sociedade industrial impulsionada economicamente pelo capitalismo de mercado, sob a forma política de democracia liberal em consonância com a visão nacional-desenvolvimentista e pelo populismo. Os principais ideólogos do nacional-desenvolvimentismo eram os pensadores do Instituto Superior de Estudos Brasileiros (ISEB), sendo que, para eles, a burguesia seria a classe apta (naquele momento histórico) a comandar as reformas de base que conduziriam o país ao desenvolvimento, ademais, as práticas do populismo, herança de Vargas, somam-se às ideias dos isebianos (RUCKSTADTER; SOUZA, 2020).

Dessa maneira, no contexto histórico referido, Freire considerava que a industrialização capitalista, o progresso e a democracia vigente poderiam conduzir o Brasil a ser autônomo e independente. Por sua vez, o governo tinha interesse no método de alfabetização de Freire, já que a ideia era alfabetizar em 40 horas de trabalho e, nesse período, o governo via vantagem nessa alfabetização do povo, visando seus próprios interesses eleitorais. Freire também teve influência das ideias progressistas da Igreja, principalmente ligadas à Teologia da Libertação. Ainda no Chile, após concluir a obra Educação como prática da liberdade, o educador começou a redação de Pedagogia do Oprimido, aquela que é considerada sua obra mais conhecida e importante, sendo concluída em I968 (RUCKSTADTER; SOUZA, 2020). Nesta obra, está presente outra fase do pensamento freiriano, em que ele faz uma abordagem de opressor versus oprimido, pensando na educação mergulhada no conflito das classes sociais; embora se façam notar alguns elementos do marxismo, o personalismo cristão não deixa de estar presente (BEISIEGEL, 20I0).

Em 1969, Freire foi proibido de continuar seu trabalho no Chile, já que por lá também começava o processo para se instalar uma Ditadura Militar. Então, foi com a família para os Estados Unidos, onde lecionou em Harvard, até fevereiro de 1970. Em 1970, transferiu-se para Genebra, na Suíça, tendo atuado como consultor do Departamento de Educação do Conselho Mundial das Igrejas, 
Vanessa Campos Mariano Ruckstadter, Flávio Massami Martins Ruckstadter e Gabriely Cristine de Souza morando lá por vários anos. Em 1980, Paulo Freire pôde, finalmente, retornar para o Brasil (SAVIANI, 20I3).

Dessa maneira, percebe-se que, enquanto era proibido de retornar para seu país, o educador era procurado e reconhecido por pessoas de todo o mundo. Seu retorno ao Brasil se deu no contexto da redemocratização (neste país, a democracia parece estar sempre sendo reconstruída). Além do mais, nas palavras de Saviani (20I3, p. 4I4), "[...] a "transição democrática” fez-se, pois, segundo a estratégia da conciliação pelo alto, visando a garantir a continuidade da ordem socioeconômica".

No retorno ao Brasil, com 59 anos de idade, Freire e sua família residiram em São Paulo, sendo que o educador lecionou na PUC-SP e na Universidade Estadual de Campinas (UNICAMP), além de ser professor-visitante na Universidade de São Paulo (USP), em 1991. Ele deu sequência às suas produções de livros, artigos, ensaios, entrevistas e conferências até o ano de 1997. Podem-se destacar, entre suas obras mais recentes, Pedagogia da esperança, de 1992, Política e educação, publicada em 1993 e Pedagogia da autonomia, em 1996. (SCOCUGLIA, 2019). Pouco antes de falecer, Paulo Freire disse, em algumas conversas, que queria ser lembrado como alguém que amou o mundo, as pessoas, os bichos, as árvores, a vida. O educador Paulo Freire partiu em maio de 1997, com 76 anos de idade (RUCKSTADTER; SOUZA, 2020).

No método de Paulo Freire, o termo Círculo de Cultura entra no lugar de classe, pois a classe de alfabetização dá um sentido de sobreposição do professor, entrando na chamada Educação Bancária tão criticada pelo educador, em que um professor "transfere" conhecimento seu para o aluno, que só recebe. Assim, seguindo o contexto e as ideias de Freire, pode-se apreender que ele e seus colegas colaboradores deram visibilidade à cultura, à educação do povo, que havia sido historicamente invisibilizada pela cultura dominante. Freire destaca uma politização maior nas perguntas, nas reflexões sobre os objetos do conhecimento, em um maior questionamento, com ênfase no diálogo nos processos de ensino-aprendizagem.

Vale destacar que Freire não escondia sua preferência pelo Círculo de Cultura em lugar da Aula, pelo animador(a) cultural em lugar do(a) professor(a) tradicional, mas não condenava, de maneira alguma, a aula, o(a) professor(a) e/ou a escola formal (ROMÃO, 20I8a). Parte-se da compreensão de que seu método de alfabetização é fundamentado em um pensamento educacional e de mundo amplo, em que sempre predominam as ideias de uma educação democrática, libertadora e crítica.

Paulo Freire tinha esperança, esperança na educação, esperança nas pessoas, para ele a esperança faz parte da natureza humana, é ontológica. Alcançar a esperança para o autor deve partir do entendimento de que a história não é determinista, mas sim, uma possibilidade. (GIROUX, 20I8). Além disso, somos seres em uma permanente tensão entre $\circ$ que somos efetivamente e $\circ$ que gostaríamos de ser (ROMÃO, 20I8b). 
“Ensinar exige liberdade e autoridade": os conceitos freirianos de autoridade, liberdade, disciplina e autonomia

Considerando os pressupostos acima, o pensamento de Paulo Freire contribui para diversas reflexões a respeito de uma educação democrática, libertadora e crítica, em contrapartida à tradicional educação, que o educador denomina de "Bancária". A educação bancária se constitui em uma narrativa alienada e alienante, com a perspectiva de educar para a submissão, para a visão de um sujeito acabado, concluso e determinado (FREIRE, 1987).

Nessa perspectiva, seu pensamento colabora para a discussão sobre a disciplina e indisciplina na sala de aula. Autoridade e autoritarismo não podem ser tomados como sinônimos:

Autoridade é tudo que faz com que as pessoas obedeçam. Assim, na instituição escolar, uma pessoa, investida da função de professor, adquire o poder de determinar as ações dos alunos, que legitimam esse poder, pois trazem de casa, ou adquirem rapidamente, a imagem do professor como autoridade. Porém, o modo como o professor exerce a sua autoridade em sala - se de forma autoritária ou liberal [...] é vital para o estabelecimento (ou não) de uma situação de disciplina em sua turma (NOVAIS, 2004, p. 17).

A obediência, quando se dá por meio do autoritarismo, ocorre por obrigação, por medo de punições, por coerção e não por respeito à figura do docente. Assim, essa obediência por medo e repressão causa um confronto em sala de aula, pode gerar sentimentos que não favorecem o trabalho pedagógico, tais como hostilidade, ressentimentos, inferioridade e passividade (NOVAIS, 2004, p. 2I).

A educação autoritária esteve presente na organização escolar brasileira em outros contextos. Ela favorece um comportamento submisso, sem uma educação crítica, na qual os alunos não são estimulados a pensar ou expor suas opiniões, sem diálogo. Essa situação pode favorecer um comportamento ainda mais indisciplinado, de revolta.

O primeiro tipo de autoridade, a autoritária [...] é historicamente associado à organização escolar, seja relacionado à educação religiosa ou militar, que dominou, por muito tempo, o trabalho pedagógico. [...] Sua característica principal é que os alunos, ao obedecerem, não o fazem por acreditar na autoridade docente, mas sim porque são obrigados, não têm escolha, ou seja, obedecem, mas não respeitam, gerando assim um círculo vicioso: os estudantes não respeitam o professor, que se torna mais autoritário e utiliza mais instrumentos de coação, gerando mais indisciplina e consequentemente menos respeito por parte dos alunos. Neste sentido, a autoridade autoritária, decorrente de uma posição hierárquica, pode ser "aceita" simplesmente porque a lei ampara e não porque seu portador demonstra competência ou liderança [...] Assim, o professor autoritário deixa claro ao aluno que, se não fizer o que é mandado, sofrerá sanções (NOVAIS, 2004, p. 2l).

Diferentemente da autoridade autoritária, há a autoridade liberal, que legitima a autoridade do professor, já que ele possui um conhecimento de como auxiliar os estudantes e um domínio sobre os saberes sistematizados a que se propôs a ensinar, essa responsabilidade já confere ao docente uma 

autoridade. Porém, diferente do autoritarismo, essa autoridade não abusa de seu poder, estando nos limites da democracia. Assim, ocorre um diálogo com os alunos, que podem dar suas opiniões e terem um ensino crítico, a obediência que advém dessa autoridade é relacionada ao respeito pelo docente. Dessa forma, "a autoridade do professor é vista como poder legitimado pelas partes envolvidas, que surge da aliança entre o conhecimento e a experiência na condução da classe, buscando orientar o indivíduo, ajudar o aluno a crescer social, psicológica e intelectualmente [...]” (NOVAIS, 2004, p. 26).

Nesse contexto, é válido mencionar sobre a assimetria na relação entre educador e educando. $\mathrm{O}$ educador deve assumir a diferença entre ambos, mas, ao dialogar com os estudantes, faz jus à autoridade que é inerente à sua função social. Essa relação entre a assimetria e a autoridade foi analisada por Novais (2004) e Carvalho (2015). Assim sendo, a autoridade, apesar de ser uma forma de poder, não deve ser confundida com o autoritarismo. A autoridade é relacionada com o respeito e é necessária para manter a disciplina em sala de aula. A disciplina também não deve ser confundida com silêncio total e passividade, mas com respeito a algumas regras para se manter o objetivo pedagógico. Bem como a liberdade, que é muito defendida por Freire (1996), necessária para uma educação democrática e que não inibe a curiosidade do discente, não pode ser confundida com licenciosidade, que não possui limites. Dessa forma, é necessário ter um equilíbrio dentro da sala de aula entre disciplina e liberdade, autoridade e licenciosidade.

Feitas algumas considerações a respeito dos conceitos de autoridade, autoritarismo, disciplina, liberdade e licenciosidade, vale fazer uma análise desses conceitos, acrescida de outros conceitos, como o de Práxis, Autonomia e Diálogo, de acordo com o pensamento de Paulo Freire, especificamente em sua obra Pedagogia da Autonomia (1996).

A autoridade do professor é necessária, porém, ela pode ser autoritária ou liberal. Para Freire (1996), o essencial seria o equilíbrio. A autoridade autoritária utiliza-se de meios coercitivos e repressores, do castigo e da ameaça. A postura da autoridade liberal não deixa o professor ser repressivo, como um professor autoritário, mas também não deixa ele ser conivente com a indisciplina do aluno, como um professor licencioso. A autoridade liberal pressupõe a segurança do professor no que está ensinando e também um diálogo com os estudantes. Essa relação deve se dar a partir do respeito dos alunos, mas não o medo. $O$ aluno deve ser capaz de produzir uma formação autônoma, mas comprometida com a construção de uma vida humanamente digna para todos e todas. Defendendo a presença da autoridade legítima do professor e da professora, é preciso ter respeito também à autonomia de ser do educando, que é um dos saberes necessários à prática educativa, dimensão que é inteiramente antropológica, pois não é possível pensá-la sem admitir a inconclusão do ser que se sabe inconcluso (PITANO; GHIGGI, 2009).

Olhar de professor, Ponta Grossa, v. 24, p. I-2I, e-16762.040, 2021. 
Paulo Freire (1996), em Pedagogia da Autonomia, elabora alguns saberes necessários à prática educativa. Um desses saberes é que, para o docente ensinar, é necessário ter consciência de que o ser humano é inacabado, inconcluso. Tudo o que possui vida é inacabado, mas só os seres humanos podem ter consciência desse inacabamento. Ademais, o ser humano é condicionado pelo contexto sociocultural histórico em que se vive, mas isso não está determinado, a sociedade está sendo assim, ela não é assim. Dessa forma:

Inacabado, sei que sou um ser condicionado, mas, consciente do inacabamento, sei que posso ir mais além dele. Esta é a diferença profunda entre o ser condicionado e o ser determinado. A diferença entre $\circ$ inacabado que não se sabe como tal e o inacabado que histórica e socialmente alcançou a possibilidade de saber-se inacabado (FREIRE, 1996, p. 23).

Com a compreensão de que é condicionado, mas não determinado, o ser humano tem a consciência de que, por ser inacabado, pode tornar as coisas diferentes do que estão sendo. $\mathrm{E}$ a educação que Freire propôs, a educação libertadora, é fundamental para isso, já que essa educação faz com que as pessoas deixem de ser o que são, para se tornarem mais conscientes, mais humanas e mais livres.

É na inconclusão do ser, que se sabe como tal, que se funda a educação como processo permanente. Mulheres e homens se tornaram educáveis na medida em que se reconheceram inacabados. Não foi a educação que fez mulheres e homens educáveis, mas a consciência de sua inconclusão é que gerou sua educabilidade. É também na inconclusão de que nos tornamos conscientes e que nos inserta no movimento permanente de procura que se alicerça a esperança [...] (FREIRE, 1996, p. 24).

Assim, é através da consciência crítica do seu inacabamento que as pessoas entendem a necessidade da atuação prática para transformar a realidade social condicionante, para transcender a si mesmas em busca do ser mais. Para que isso ocorra, Freire pensa no conceito de Práxis. A simples tomada de consciência não é suficiente, ela precisa de uma reflexão e de uma ação constante. Esse pensamento de Freire é mais bem explicado por Zitkoski (2018a, p. 96-97):

[...] O processo de elaboração/construção/atualização do conhecimento requer, além da tomada de consciência, a radicalidade dialética que produz o constante tensionamento entre reflexão-ação, teoria-prática, discurso-inserção na realidade. Sem esse processo de tensionamento e síntese entre os dois polos dialéticos, a curiosidade epistemológica não se completa, atrofiando, assim, o potencial de transcendência do horizonte da consciência e ocasionando também certa cristalização da visão de mundo por falta da inserção prática do ser humano na realidade que o está condicionando. Ou seja, as situações limites que desafiam o potencial de realização de uma existência mais livre, consciente e responsável pela sua história, não poderão ser transpostas na teoria apenas. É a práxis transformadora da realidade, como construção dialética do mundo e dos próprios sujeitos (pessoas humanas) que caracteriza $\circ$ processo de conscientização e o diferencia da simples tomada de consciência (ZITKOSKI, 2018a, p. 96-97). 
Nesse contexto, a educação proposta por Freire pressupõe a Práxis. Ela pressupõe que, para ensinar, é preciso ter respeito à autonomia do ser do educando: “[...] O inacabamento de que nos tornamos conscientes nos fez seres éticos. O respeito à autonomia e à dignidade de cada um é um imperativo ético e não um favor que podemos ou não conceder uns aos outros [...]" (FREIRE, 1996, p. 24-25).

O conceito de Autonomia permeia toda a discussão sobre a postura do professor em sala de aula, a questão da autoridade e do autoritarismo, da liberdade e da licenciosidade. A Autonomia é um ensinar a pensar certo, é um ato comunicante, coparticipado, é libertar o ser humano das cadeias do determinismo neoliberal, uma vez que o poder dominante arquiteta toda uma estrutura para se manter no poder, fazendo com que as pessoas pensem que tudo já está determinado, naturalizando até as injustiças sociais (FREIRE, 1996). Dessa maneira, ao ter Autonomia, o estudante pode reconhecer que a história é um tempo de possibilidades. Ademais, "Todo processo de autonomia e de construção de consciência nos sujeitos exige uma reflexão crítica e prática, de modo que o próprio discurso teórico terá de ser alinhado a sua aplicação" (MACHADO, 2018, p. 6I).

A Autonomia possui, então, como fundamental, a ação de assumir a passagem da curiosidade ingênua para a curiosidade epistemológica, o modo de viver, de agir, de aprender e de ensinar de maneira crítica, libertadora e democrática. Com tudo isso, é válido dizer que, para Freire, a discussão sobre a Autonomia é a meta no processo educativo, uma vez que o educador considera a Autonomia como o ponto de equilíbrio que pode estabelecer a legitimidade da autoridade e da liberdade (PITANO; GHIGGI, 2009). Para a construção da Autonomia é necessário que a pessoa esteja "centrada em experiências estimuladoras da decisão e da responsabilidade, vale dizer, em experiências respeitosas da liberdade" (FREIRE, 1996, p. 4I).

A partir da análise dos regulamentos de algumas escolas cívico-militares, percebe-se que elas ferem a autonomia do educando, utilizando do conceito de disciplina e respeito às normas de forma autoritária. No regimento do Colégio Ayrton Senna, em Goiânia, uma série de "transgressões" relacionadas à aparência e ao comportamento são elencadas, tais como a forma como os cabelos devem ser cortados e/ou presos, unhas devidamente uniformizadas/padronizadas, e proibição na promoção ou participação de manifestação coletiva que possa macular o nome da instituição, o bom andamento das aulas ou avaliações. Esses termos são usados de forma genérica, mas impedem a expressão das individualidades e podem dar margem à censura. Isso levou o Ministério Público Federal da Bahia a questionar a constitucionalidade desse tipo de escola, uma vez que ela impõe padrões estéticos dos militares e não há relação entre essa padronização e a melhoria do ensino e da aprendizagem, além de dar margem à censura. O MPF/BA ainda atenta para o fato de que esse tipo de escola pode impactar toda a comunidade escolar e sociedade, pois barram a 
liberdade de realizar a crítica, bem como a pluralidade de ideias, o que daria margem ao controle do Estado e de seus agentes (REZENDE; BRAGA; GARCIA, s.d.).

A crítica referenciada neste texto não é sobre as normas e regras em si, já que essas são necessárias para um convívio social, para o trabalho pedagógico, mas é sobre seu aspecto autoritário e opressor, sobre o fetiche da ordem como necessária ao aprendizado.

Tendo presente que há um "hábito da produção coletiva de normas", enquanto estrutura e cultural enraizada no mundo escolar, Freire encoraja a perguntar pela acelerada fetichização da ordem. Ou seja, a escola não pouco acolhe educandos e os induz a comportamentos que silenciam desejos e a expressão do mundo no qual se formaram. [...] (GHIGGI, 20I8a, p. 149).

Não é a primeira vez na história do país que esse modelo de escola é apresentado:

Esse modelo militarizado de escolas e suas práticas autoritárias traz ao Brasil democrático lembranças da Ditadura Militar que vigorou no Brasil de 1964 a 1985. Como exemplo, tem-se que foi nesse período em que as escolas passaram a ter vidros nas portas das salas de aula a fim de trazer uma ideia de constante vigilância e medo das punições causadas pela "indisciplina". Assim como nesse momento, o plano de militarização das escolas adota a mesma estratégia: a de disciplina pelo medo e pela coerção (REZENDE; BRAGA; GARCIA, s.d., s.p.).

Há uma necessidade de equilíbrio. Equilíbrio na postura do professor em sala de aula, na sua postura com os educandos. É necessário um equilíbrio na autoridade de professor, para não se tornar um professor autoritário, mas também é necessário um equilíbrio na liberdade que tem para com os estudantes, para não se tornar um professor licencioso. É preciso ter uma postura da autoridade libertadora, que respeita a Autonomia do educando, que propõe um diálogo e uma educação crítica, mas com limites, sem perder a essência do trabalho pedagógico e o respeito dos estudantes (FREIRE, 1996).

O pensamento de Paulo Freire é radicalmente oposto ao modelo de educação tradicional ou desse modelo cívico-militar. Para entender o conceito de disciplina para o educador pernambucano, é importante distinguir que disciplina, para a educação tradicional, serve para impor aos discentes o respeito à ordem estabelecida pela sociedade, com o objetivo de naturalizar as imposições e fixar uma conformidade para que os estudantes obedeçam ao poder instituído. Diferentemente, para Freire, a disciplina está associada à autonomia dos sujeitos, a uma disciplina na leitura, no ato de ensinar e aprender, no cotidiano da escola, no respeito e no trato da coisa pública, na própria denúncia da desumanidade instalada no humano e no engajamento em ações coletivas (GHIGGI, 20I8a).

O projeto das escolas cívico-militares embasa-se por um discurso da "ordem" e da "disciplina". Intenta padronizar, uniformizar, retirar a possibilidade de manifestações de liberdade de expressão e, com punições para comportamentos considerados inadequados, coíbe e rejeita a 
pluralidade e a diversidade. Trata-se da manutenção da estrutura dominante. Há uma confusão e utilização dos conceitos de autoridade e de disciplina, como se fossem equivalentes ao conceito de autoritarismo. Ainda, há uma confusão entre a liberdade que se tem na sala de aula com a licenciosidade de um professor.

Cabe rememorar que a marca do autoritarismo é a rejeição de pluralidade e da diversidade, tratadas como ameaças, em favor de ordem, a ser mantida inclusive pelo uso da força. Um projeto de educação que privilegia a obediência e pune a autonomia deve, portanto, ser lido com a devida crítica. Assim, é possível notar que o autoritarismo que se instala nessas instituições, fantasiado de disciplina, se apresenta como base para a construção de uma realidade pautada no medo, na dissolução de direitos e na demonização da democracia no ensino público (REZENDE; BRAGA; GARCIA, s.d., s.p.).

Freire (1996) defende que, para que o educando tenha uma educação democrática, libertadora e crítica, é necessário que a postura adotada pelo professor seja igualmente democrática, que ele tenha a autoridade legítima como docente, mas que ofereça uma liberdade para os estudantes, mediados pelo diálogo.

O professor que desrespeita a curiosidade do educando, o seu gosto estético, a sua inquietude, a sua linguagem, mais precisamente, a sua sintaxe e a sua prosódia; $\circ$ professor que ironiza o aluno, que o minimiza, que manda que "ele se ponha em seu lugar" ao mais tênue sinal de sua rebeldia legítima, tanto quanto o professor que se exime do cumprimento de seu dever de propor limites à liberdade do aluno, que se furta ao dever de ensinar, de estar respeitosamente presente à experiência formadora do educando, transgride os princípios fundamentalmente éticos de nossa existência. É neste sentido que o professor autoritário, que por isso mesmo afoga a liberdade do educando, amesquinhando o seu direito de estar sendo curioso e inquieto, tanto quanto $\circ$ professor licencioso rompe com a radicalidade do ser humano - a de sua inconclusão assumida em que se enraíza a eticidade. É neste sentido também que a dialogicidade verdadeira, em que os sujeitos dialógicos aprendem e crescem na diferença, sobretudo, no respeito a ela, é a forma de estar sendo coerentemente exigida por seres que, inacabados, assumindo-se como tais, se tornam radicalmente éticos (FREIRE, 1996, p. 24-25).

Nesse sentido, é primordial que o professor, especificamente no Brasil, supere a herança que o conceito de disciplina carrega, uma herança que o tornou ligado com o autoritarismo, com a submissão do estudante, que não se expressa, não reflete sobre o que aprende, apenas recebe o conhecimento que, na maioria das vezes, não é interiorizado. A disciplina escolar "[...] é um conjunto de normas de comportamento que são fundamentais para o funcionamento da escola, mas onde nem sempre o silêncio é sinônimo de disciplina" (BEDENE; DIAS, 20I2, p. I0).

Destarte, uma sala de aula mais barulhenta pode ser resultado de um bom relacionamento entre professor e aluno, em que o barulho é apenas uma animação manifestada pelos estudantes durante o processo de ensino-aprendizagem. Por outro lado, em salas de aula silenciosas demais, pode estar ocorrendo uma manifestação de medo por parte dos alunos, com relação a um professor 
autoritário, que não possui o respeito dos seus alunos, mas o medo, devido a suas atitudes coercitivas, ameaçadoras e repressivas, que impede qualquer manifestação de reflexão e de expressão sobre o conhecimento (que só é depositado) por parte dos educandos (BEDENE; DIAS, 20I2).

Uma postura autoritária do professor pode gerar nos alunos um comportamento ora rebelde, desobediente a qualquer limite, autoridade ou disciplina, ora um comportamento apático, de obediência exacerbada. Assim, percebe-se que o argumento utilizado pelas escolas cívico-militares não se sustenta, já que o trabalho pedagógico e a aprendizagem dos estudantes só se prejudicam. $\mathrm{Na}$ sociedade atual, há uma tensão que oscila entre a imposição da disciplina que nega a liberdade e a ausência de disciplina pela negação da autoridade. De acordo com o pensamento de Paulo Freire, o ato de ensinar só é incômodo para professores que seguem práticas autoritárias ou licenciosas, para educadores democráticos o ato educativo, de estudar são sérios, exigem um comprometimento, um bom senso, mas não um ato autoritário (GHIGGI, 20I8b).

Por conseguinte, a autoridade precisa, juntamente com a liberdade, estabelecer uma relação de harmonia. A disciplina exige ambas, o respeito de uma pela outra na assunção dos limites que cabem a cada uma não transgredir. Logo:

O autoritarismo e a licenciosidade são rupturas do equilíbrio tenso entre autoridade e liberdade. $\mathrm{O}$ autoritarismo é a ruptura em favor da autoridade contra a liberdade e a licenciosidade, a ruptura em favor da liberdade contra a autoridade. Autoritarismo e licenciosidade são formas indisciplinadas de comportamento que negam o que venho chamando a vocação ontológica do ser humano (FREIRE, 1996, p. 34).

Os professores, enquanto seres portadores dessa autoridade devem assumir e lutar por essa concepção de autoridade. É necessário um comprometimento de caráter social, cultural, político com a sua classe profissional e a classe trabalhadora em geral. Buscar por todos esses aspectos é ter um compromisso social. A respeito da concepção da autoridade nesse trabalho pedagógico, Bedene e Dias (2012, p. 12) asseguram que:

\begin{abstract}
A autoridade do trabalho pedagógico na relação entre professor e aluno é uma autoridade construída pela mediação do conhecimento traduzido nesses dois aspectos da formação do professor (competência científica e técnica e o compromisso social). Quem outorga essa autoridade também é um sujeito portador da autoridade de educando. É assim que deve ser compreendido o aluno, como um sujeito portador de autoridade. A mediação dialógica entre essas duas autoridades e - papel de cada uma, expressa exatamente o que é a natureza da autoridade pedagógica na relação entre professor e aluno. Isso requer, por outro lado, a compreensão de cada aluno como portador de uma subjetividade, de um mundo em construção (BEDENE; DIAS, 2012, p. 12).
\end{abstract}

Essa autoridade, defendida por Freire (1996), está a serviço da liberdade e da autonomia do educando. Desse modo, sobre a autoridade libertadora, que possibilita ao educador e ao educando 

a construção da Autonomia. Pitano e Ghiggi (2009, p. 87) ressaltam que "[...] a autonomia é construída, em relação à formação escolarizada, frente a capacidade que o educador tem de atuar com segurança, com competência profissional e com generosidade. Esse é o pressuposto para o exercício da autoridade libertadora ou a serviço da formação para a liberdade".

Cabe destacar que a liberdade que Paulo Freire defende não é uma liberdade sem limites, já que, para o educador, uma liberdade sem limites é tão negativa quanto a liberdade que é asfixiada. E é nessa perspectiva que ele defende a construção de uma Autonomia, "Autonomia essa que, além de histórica, constrói-se na criatividade e na tensa relação entre liberdade e autoridade" (PITANO; GHIGGI, 2009, p. 87). Essa liberdade também deve ser buscada, conquistada, por isso é necessário lutar por ela. A liberdade e a autonomia são conquistadas nas decisões coletivas, e, é decidindo com os outros, que o educando (e o educador também) aprende a decidir. Dessa maneira, de acordo com Paulo Freire, a Autoridade, a Liberdade e a Autonomia são construções inseparáveis, partindo-se da ideia de que o processo de ensino-aprendizagem na escola não é separado do resto do mundo e da vida do estudante. $O$ processo de ensino-aprendizagem é também um ato de intervenção no mundo (PITANO; GHIGGI, 2009).

A liberdade é negada em sistemas sociais injustos, que querem manter a estrutura social como está, manter o seu poder, por isso a necessidade de formar estudantes que não refletem, não criticam, pelo contrário, obedecem a essa ordem imposta, que é dada como natural e determinada. Para isso, os que possuem o poder utilizam do discurso de manter uma "ordem" e uma "disciplina" nas salas de aula, como mencionado anteriormente. Freire (1996) defende a luta por essa liberdade, pela libertação dessas condições, já que o ser humano não é determinado, e sim condicionado e inacabado, podendo a sociedade vir a ser de outra maneira. Essa luta é possível também porque é ontológico no ser humano ser esperançoso e não acomodado e subserviente.

A liberdade não se opõe à liberdade alheia, como na vontade despótica 「a vontade dos que possuem o poder dominante, que é uma liberdade egoísta, que nega outras vontades], nem termina onde começa a liberdade do outro, mas se realiza quando se encontra com outras pessoas na luta pela própria liberdade e pela das outras (SUNG, 2018a, p. 289).

Essa luta permanente pela liberdade ocorre no âmbito da interioridade humana, da consciência e do desejo, e no âmbito sociopolítico, isto porque há uma interiorização do opressor no oprimido, decorrente da cega obediência a ordem vigente e da naturalização da estrutura social, bem como a colonização da consciência da elite brasileira que alienam e reproduzem o sistema vigente que oprime e se contrapõe à realização da vocação humana para humanização e liberdade. Desse modo, essa luta é essencial para a superação das relações de opressão e a liberdade é conquistada quando se luta pela libertação não só de si, mas do mundo (SUNG, 20I8a). 
No entanto, o conceito de liberdade de Paulo Freire não pode ser confundido com a licenciosidade. A licenciosidade não pressupõe limites e acaba se tornando egoísta por não respeitarem as vontades e os desejos de outras pessoas.

O que sempre deliberadamente recusei, em nome do próprio respeito à liberdade, foi sua distorção em licenciosidade. $O$ que sempre procurei foi viver em plenitude a relação tensa, contraditória e não mecânica, entre autoridade e liberdade, no sentido de assegurar o respeito entre ambas, cuja ruptura provoca a hipertrofia de uma ou de outra (FREIRE, 1996, p. 4I).

O conceito de liberdade freiriano pressupõe que a liberdade como conquista do ser humano na realização da sua vocação de humanização ocorre quando os sujeitos assumem seus limites. Isso porque, quando os sujeitos não aceitam seus limites, tendem a impor suas vontades ilimitadas, de maneira despótica e egoísta sobre as vontades e os direitos de outras pessoas, assim, assumem uma licenciosidade que pode levar a um autoritarismo e não a uma liberdade, já que a liberdade dispõe de uma disciplina (no sentido freiriano) e de uma democracia (SUNG, 20I8b).

Ainda analisando os conceitos freirianos a partir de Pedagogia da Autonomia, Freire (1996) propõe que $o$ ato de ensinar exige Liberdade e Autoridade. $O$ educador reconhece que não foi superado o problema da tensão entre esses dois conceitos, uma vez que alguns professores, para superar a tradição autoritária, acabam assumindo posturas licenciosas, enquanto outros professores, para não serem licenciosos, acabam tornando-se autoritários.

Sobre essas relações das posturas adotadas pelos professores nas salas de aula:

É interessante observar como, de modo geral, os autoritários consideram, amiúde, o respeito indispensável à liberdade como expressão de incorrigível espontaneísmo e os licenciosos descobrem autoritarismo em toda manifestação legítima da autoridade. A posição mais difícil, indiscutivelmente correta, é a do democrata, coerente com seu sonho solidário e igualitário, para quem não é possível autoridade sem liberdade e esta sem aquela (FREIRE, 1996, p. 4I).

A posição defendida por Paulo Freire (1996) é a do educador democrata que assume o equilíbrio, a harmonia entre a Autoridade e a Liberdade, que devem se avaliar entre si. Essa é a postura a favor do ensino-aprendizagem dos educandos, já que propõe um aprendizado científico, mas com compromisso social, com reflexões e com diálogo, em que os educandos respeitam, e não temem, o professor.

O grande problema que se coloca ao educador ou à educadora de opção democrática é como trabalhar no sentido de fazer possível que a necessidade do limite seja assumida eticamente pela liberdade. Quanto mais criticamente a liberdade assuma o limite necessário tanto mais autoridade tem ela, eticamente falando, para continuar lutando em seu nome (FREIRE, 1996, p. 40).

Olhar de professor, Ponta Grossa, v. 24, p. I-2I, e-16762.040, 202 I.

Disponível em <https://revistas2.uepg.br/index.php/olhardeprofessor> 
Vanessa Campos Mariano Ruckstadter, Flávio Massami Martins Ruckstadter e Gabriely Cristine de Souza

Outro conceito importante é o de diálogo. O diálogo, para Paulo Freire (1996) é indispensável para a formação da autonomia. Para o educador que assume uma postura da autoridade liberal, o diálogo é essencial para essa posição. Em uma situação que há diálogo, há a ausência do autoritarismo. O diálogo permite que o "[...] educando, na criação dialógica, encontrase a caminho da formação para a autonomia. É, o diálogo, a condição de possibilidade para a problematização do senso comum, das ingenuidades, tanto do educando quanto do educador [...]” (PITANO; GHIGGI, 2009, p. 91).

O diálogo é fundamental na proposta de educação libertadora e humanista que Freire (1996) propõe. Essa educação humanizadora defendida pelo educador é uma alternativa contra-hegemônica a favor da Autoridade e da Liberdade, da Autonomia e da Disciplina. A dialogicidade é uma prática importante nessa educação humanizadora. Para a prática educativa, nesse raciocínio, é preciso uma abertura para o outro, não no sentido da tolerância, mas de ir além dela, no sentido de respeitar, de conviver com as diferenças e de superar as situações-limites, as condições impostas. Essa abertura "só pode efetivar-se pelo diálogo crítico e criativo em relação à existência humana concreta" (ZITKOSKI, 20I8b, p. I4I).

A educação proposta por Freire (1996) é uma educação problematizadora, que encoraja os estudantes a pensarem e a agirem sobre seus mundos, e essa educação problematizadora necessita que o professor assuma a postura da autoridade libertadora, com o diálogo e com consciência crítica: "problematizar é pensar coletivamente, organizando o saber popular acrescido do conhecimento científico, associando a outros temas, contextualizando no tempo e no espaço e, conforme o diálogo vai se estabelecendo, as 'inverdades' vão sendo destruídas, e a realidade passa a ser desvelada" (CITTOLIN; CLARO, 2013, p. 28392).

Vale frisar que a trajetória biográfica e intelectual de Paulo Freire:

Foi profundamente marcada pela preocupação com a efetivação de um processo educativo, com base no diálogo, que além de promover o acesso aos conhecimentos humanos acumulados, propiciasse a libertação da consciência humana, de tal forma que a emancipação do sujeito possa the fornecer plenas condições de atuar em seu contexto social promovendo as transformações necessárias para a sua permanente construção e humanização (CITTOLIN; CLARO, 2013, p. 28388).

Conseguinte, ao contrário do modelo autoritário de educação, o modelo pensado pelo educador pernambucano tem o diálogo como base. Educador e educando realizam juntos uma leitura crítica do mundo, pensando na transformação constante da realidade e das pessoas, que, inacabadas, podem tornar a sociedade diferente do que está sendo, na busca de sua liberdade (no sentido freiriano) e da justiça social. O conhecimento é construído através da interação e o diálogo é base para uma educação problematizadora (CITTOLIN; CLARO, 20I3). 
O educador que possui uma autoridade autoritária não dialoga, não se comunica, ele faz "comunicados" e deposita respostas prontas para a solução de problemas (que, muitas vezes, o aluno nem interioriza, não aprende), e os educandos devem receber de maneira subserviente e paciente, memorizar e repetir essas respostas. Paulo Freire faz uma crítica a esse procedimento, já que:

[...] os educandos sofrem com a ausência do diálogo, pois a relação educadoreducando se faz de forma vertical, de cima para baixo, na pretensão de definir aqueles que sabem e, portanto, tem o poder, e aqueles que não sabem, realçando assim as diferenças que são vistas como entraves ao desenvolvimento (CITTOLIN; CLARO, 2013, p. 28393).

Em uma educação que não considere o diálogo, a mudança é entendida como impossível de acontecer, restando-se a adaptação à realidade. No entanto, Freire (1996) possui outra visão, a de que o ser humano é inacabado, e com a consciência do seu inacabamento, pode transformar a sociedade, como supracitado.

Como alternativa contra-hegemônica comprometida com a mudança, Paulo Freire propõe que educador e educando realizem juntos uma leitura crítica do mundo.

Freire reconhece no diálogo um caminho viável de comunicação que tem como uma de suas finalidades romper com esquemas verticais de relações, com relações autoritárias, de cima para baixo, pois estas, que teriam como pretensão coibir atos considerados de indisciplina, acabam por provocar o contrário, isto é, criam ainda mais conflitos. E por mais que sejam reconhecidos como oportunidades de crescimento, a maneira como os conflitos são tratados, mediados e resolvidos, determinam as possibilidades de paz ou de violências. Nesse outro modelo, então, a educação ocorre numa relação horizontal em que educador e educando estabelecem constante diálogo, não invadindo, nem manipulando, mas empenhando-se na transformação constante da realidade. e, como explicitam (CITTOLIN; CLARO, 2013, p. 28393-28394).

Uma das lições de Paulo Freire é que, assim como a educação está sendo utilizada para a opressão, para manter a estrutura social dominante, ela pode ser utilizada para a libertação, tanto dos oprimidos quanto dos opressores. Somente por meio de uma educação comprometida com a liberdade, com a humanidade, uma educação problematizadora, dialógica, na qual os educadores assumam a postura da autoridade liberal, as pessoas compreenderiam os sistemas sociais de opressão, entenderiam que a sociedade é condicionada, mas não determinada. A partir da consciência de seu inacabamento, as pessoas podem agir e mudar essa realidade que está sendo, como nos ensinou o educador, mas que poderia ser diferente na conquista de justiça social.

\section{Considerações finais}

Pode-se apreender que Paulo Freire tinha esperança na educação e na humanidade. Para ele, a esperança faz parte da natureza humana e pode ser geradora de mudança, ainda mais considerando 

que o ser humano é um ser inacabado, inconcluso, que possui a consciência de se saber inconcluso. $O$ nome do educador está muito ligado ao seu método de alfabetização de adultos, porém, esse método encontra-se sedimentado em uma base epistemológica. Desde seus primeiros textos há uma concepção de sociedade, de educação, de homem, e, sem compreender essas concepções, o método criado pelo educador não pode ser entendido em sua totalidade.

Ao analisar o pensamento educacional de Paulo Freire, compreende-se a sua proposta de educação libertadora, democrática e crítica, que é uma alternativa a projetos de educação como, por exemplo, o das escolas cívico-militares. Para Paulo Freire, a autoridade deve estar a serviço da liberdade. A alternativa apresentada por ele para a educação visa um equilíbrio, uma harmonia entre a autoridade legítima do professor e algo fundamental para uma democracia e para que o aluno possa se expressar e aprender refletindo sobre as coisas que aprende: a liberdade. Essa proposta vai na contramão da proposta das escolas cívico-militares, que utilizam do discurso da indisciplina na sala de aula e do fracasso escolar para legitimar esse modelo de escola que "disciplinaria" o aluno. No entanto, como visto, essa disciplina não é a disciplina no conceito freiriano, mas sim uma disciplina silenciadora e repressora.

Paulo Freire nos ensina que o educador precisa manter juntas a autoridade e a liberdade, sem que a autoridade se torne autoritária e sem que a liberdade se torne licenciosa. Desse modo, poderá promover uma educação libertadora e humanizadora.

Paulo Freire formulou uma teoria da ação dialógica que nos fornece ferramentas para compreender esse debate acerca da autoridade e da disciplina. Apesar das críticas atuais seu pensamento se sobressai a elas e resiste por sua consistência e relevância. Em tempos de negacionismos, autoritarismo e neofascismo, o pensamento de Paulo Freire nos ajuda a resistir e a pensar a educação em sentido contra-hegemônico.

\section{Referências}

BEDENE, M. do R.; DIAS, G. da S. Disciplina e autoridade versus Indisciplina e autoritarismo: a necessária separação entre $\circ$ joio e $\circ$ trigo no trabalho pedagógico. Programa de Desenvolvimento Educacional - PDE, Curitiba - PR, v. I, s.P., 20I2.Disponível em: http://www.diaadiaeducacao.pr.gov.br/portals/cadernospde/pdebusca/producoes_pde/2010/2010_ufpr _ped_artigo_marialva_do_rocio_bedene.pdf. Acesso em: I5 mar. 202I.

BEISIEGEL, C. de R. Paulo Freire. Recife: Fundação Joaquim Nabuco/Massangana, 2010.

BEM PARANÁ. Governo lança o programa das escolas cívico-militares no Paraná. Disponível em: $\quad$ https://www.bemparana.com.br/noticia/governo-lanca-hoje-o-programa-das-escolas-civicomilitares-no-parana\#.YDjxMLhKjlU. Acesso em: 26 fev. 2021.

BRANDÃO, C. R. História do menino que lia o mundo. I. ed. São Paulo: Expressão Popular, 2014.

Olhar de professor, Ponta Grossa, v. 24, p. I-2I, e-16762.040, 2021.

Disponível em <https://revistas2.uepg.br/index.php/olhardeprofessor> 
CARVALHO, J. S. F. de. Autoridade e educação: o desafio em face do ocaso da tradição. Revista Brasileira de Educação, Rio de Janeiro, v. 20, n. 63, p. 975-993, 2015.

CITTOLIN, S. F.; CLARO, A. L. de A. O diálogo, em contraposição ao autoritarismo, para uma educação para a paz na perspectiva de Paulo Freire. In: CONGRESSO NACIONAL DE EDUCAÇÃO - EDUCERE, II, 2013, Curitiba. Anais [...] Curitiba: Champagnat, 20 I3. p. 28387-28396.

FREIRE, P. Pedagogia da autonomia: saberes necessários à prática educativa. 25. ed. São Paulo: Paz e Terra, 1996.

FREIRE, P. Pedagogia do oprimido. 17. ed. Rio de Janeiro: Paz e Terra, 1987.

GHIGGI, G. Disciplina. In: STRECK, D. R.; REDIN, E.; ZITKOSKI, J. J. (Org.). Dicionário Paulo Freire. 4. ed. Belo Horizonte: Autêntica, 2018a. p. I49-I50.

GHIGGI, G. Autoritarismo. In: STRECK, D. R.; REDIN, E.; ZITKOSKI, J. J. (Org.). Dicionário Paulo Freire. 4. ed. Belo Horizonte: Autêntica, 2018b. p. 63-65.

GIROUX, H. Democracia (Reconexão do pessoal e do político). In: STRECK, D. R.; REDIN, E.; ZITKOSKI, J. J. (Org.). Dicionário Paulo Freire. 4. ed. Belo Horizonte: Autêntica, 20 I8. p. I32-I35.

MACHADO, R. de C. de F. Autonomia. In: STRECK, D. R.; REDIN, E.; ZITKOSKI, J. J. (Org.). Dicionário Paulo Freire. 4. ed. Belo Horizonte: Autêntica, 2018. p. $6 \mathrm{I}$.

MEC. Ministério da Educação. Programa Nacional das Escolas Cívico-Militares. Disponível em: http://escolacivicomilitar.mec.gov.br/. Acesso em: I3 ago. 2020.

NOVAIS, E. L. É possível ter autoridade em sala de aula sem ser autoritário? Linguagem e Ensino, Pelotas, v. 7, n. I, p. 15-5I, 2004.

PITANO, S. de C.; GHIGGI, G. Autoridade e liberdade na práxis educativa: Paulo Freire e o conceito de autonomia. Saberes, Natal, v. 2, n. 3, p. 80-93, 2009.

REZENDE, M.; BRAGA, B.; GARCIA, T. Militarização da educação: particularidades e inconstitucionalidades. Disponível em: https://cjt.ufmg.br/2019/10/09/militarizacao-da-educacaoparticularidades-e-inconstitucionalidades/. Acesso em: I3 ago. 2020.

ROMÃO, J. E. Aula. In: STRECK, D. R.; REDIN, E.; ZITKOSKI, J. J. (Org.). Dicionário Paulo Freire. 4. ed. Belo Horizonte: Autêntica, 2018a. p. 59-60.

ROMÃO, J. E. Ontologia (freiriana). In: STRECK, D. R.; REDIN, E.; ZITKOSKI, J. J. (Org.). Dicionário Paulo Freire. 4. ed. Belo Horizonte: Autêntica, 20I8b. p. 343-344.

RUCKSTADTER, V. C. M.; SOUZA, G. C. de. Um sujeito que amou profundamente o mundo e as pessoas, os bichos, as árvores, as águas, a vida: trajetória biográfica e intelectual de Paulo Freire (1921 1997). In: PEREIRA, A. L. et al. (Org.). Ágora: fundamentos epistemológicos e pesquisas avançadas em educação. Vol. 2. São Carlos: Pedro \& João Editores, 2020. p. 225-235.

SAVIANI, D. História das ideias pedagógicas no Brasil. 4. ed. Campinas: Autores Associados, 2013. 
SCOCUGLIA, A. C. A história das ideias de Paulo Freire e a atual crise de paradigmas. 7. ed. João Pessoa: Editora da UFPB, 2019.

SUNG, J. M. Liberdade. In: STRECK, D. R.; REDIN, E.; ZITKOSKI, J. J. (Org.). Dicionário Paulo Freire. 4. ed. Belo Horizonte: Autêntica, 2018a. p. 288-290.

SUNG, J. M. Licenciosidade. In: STRECK, D. R.; REDIN, E.; ZITKOSKI, J. J. (Org.). Dicionário Paulo Freire. 4. ed. Belo Horizonte: Autêntica, 2018b. p. 29I-292.

VARGAS, M. B. Governo quer 54 escolas cívico-militares até 2023; Bolsonaro defende 'impor' modelo. 2019. Disponível em: https://educacao.estadao.com.br/noticias/geral,governo-quer-54-escolas-civicomilitares-por-ano-ate-2023-bolsonaro-defende-impor-modelo,70002997979. Acesso em: 9 mar. 2020.

ZITKOSKI. J. J. Condicionado/determinado. In: STRECK, D. R.; REDIN, E.; ZITKOSKI, J. J. (Org.).

Dicionário Paulo Freire. 4. ed. Belo Horizonte: Autêntica, 2018a. p. 95-97.

ZITKOSKI. J. J. Diálogo/dialogicidade. In: STRECK, D. R.; REDIN, E.; ZITKOSKI, J. J. (Org.). Dicionário Paulo Freire. 4. ed. Belo Horizonte: Autêntica, 20I8b. p. I39-I4I.

Recebido em: 28 de agosto de 2020.

Versão corrigida recebida em: 15 de março de 2021

Aceito em: 15 de março de 2021 .

Publicado online em: 30 de abril de 2021 . 